\title{
Effects of Different Vibration Therapy Protocols on Neuromuscular Performance
}

\author{
A. Mohd Mukhtar, A. K. Abid, F. Mohd \\ Ergonomics Research Division, Department of Mechanical Engineering ZHCET, Faculty of Engineering \& \\ Technology, Aligarh Muslim University, Aligarh, Uttar Pradesh, India
}

\author{
CORRESPONDING AUTHOR: \\ Ali Khan Abid \\ Ergonomics Research Division \\ Department of Mechanical Engineering \\ ZHCET \\ Faculty of Engineering \& Technology \\ Aligarh Muslim University \\ Aligarh, Uttar Pradesh 202001 \\ India \\ E-mail: abidak71@yahoo.com
}

DOI:

10.32098/mltj.01.2021.17

LEVEL OF EVIDENCE: 1B

\begin{abstract}
SUMMARY
Background. Vibration Therapy (VT) has been attributed to the reflex activation of alpha motor neurons resulting in improved neuromuscular performance (NP).

Objective. Changes in muscular performance after VT was evaluated based on MVC grip strength, grip endurance time at 50\% MVC and EMG activities of forearm muscles, viz., flexor digitorum superficialis (FDS); flexor carpi ulnaris (FCU); extensor carpi radialis brevis (ECRB); and extensor carpi ulnaris (ECU) in supine posture.

Methods. Eight VT protocols (based on the different combinations of vibration frequency $(35$ and $45 \mathrm{~Hz}$ ), amplitude $(3 \mathrm{~g} \pm 0.5 \mathrm{~g}$ and $9 \mathrm{~g} \pm 0.5 \mathrm{~g})$ and exposure duration (30 and 60 seconds)) were given to the participants for 4 days. Participants were from two groups (56/group): persons with a sedentary lifestyle (SL) and a group of construction workers (CW).

Results. VT protocols had a significant effect on MVC grip strength $(\mathrm{p}<0.001)$, grip endurance time $(\mathrm{p}<0.05)$, \% normalized EMG rms $(\mathrm{p}<0.05)$ and neuromuscular efficiency (NME) $(\mathrm{p}<0.001)$ in all muscles for both groups. VT protocol E $(45 \mathrm{~Hz}, 3$ $\pm 0.5 \mathrm{~g}, 30 \mathrm{~s}$ ) had more positive effects on MVC grip strength for CW and less positive for SL. However, VT protocol B $(35 \mathrm{~Hz}, 3 \pm 0.5 \mathrm{~g}, 60 \mathrm{~s})$ had more positive effects on $\mathrm{CW}$ grip endurance time. In addition, the highest increase in NME was found in FDS muscle for VT protocol H $(45 \mathrm{~Hz}, 9 \pm 0.5 \mathrm{~g}, 60 \mathrm{~s})(212.8 \%)$ in $\mathrm{CW}$ and $78.55 \%$ in SL. Conclusions. VT protocols B, E, and H may be applied to workers involved in the construction industry. These interventions may improve NME, MVC grip strength, and grip endurance time. Findings may be used to form a clinical VT protocol for patients with weak muscle performances.
\end{abstract}

\section{KEY WORDS}

Vibration therapy; grip strength; endurance time; neuromuscular efficiency; electromyography.

\section{INTRODUCTION}

Recent research suggests that mechanical vibrations of low amplitudes and frequencies provide a safe and effective way to improve the neuromuscular system (1) and cause neuromuscular adaptations over a short time period without much effort (2). In the literature, vibrational intervention is also called biomechanical stimulation, biomechanical oscillation, vibration training, whole-body vibration, vibration therapy and focal vibration therapy (2-8). Initially, during a vibration intervention, a vibration device (actuator) was placed directly on the body part. Later, an oscillating platform was created so that the whole body could be stimu- lated by sinusoidal vibration. In addition, dynamic and/or static interventions are often performed on a vibrating platform or using other vibrating devices (vibrating dumbbells, vibrating massagers, spring loaded vibrating plate) $(1,3,4)$. A relatively new method of neuromuscular overload, vibration therapy (VT), has slowly emerged and gained popularity in the health sector.

The effect of VT has been attributed to the reflex activation of alpha motor neurons by stimulating muscle spindles causing muscle contraction called as tonic vibration reflex (TVR) (9). The subsequent increase in alpha motor neuron activity results in the high degree of muscle activa- 
tion, which is a sign of the improve NP $(1,3)$. Evidences for these neuromuscular adaptations has been established in several studies demonstrating an increase in electromyographic (EMG) activity after VT $(3,4,10,11)$.

There are studies, which reported the significant effects of short-term VT training on muscle strength using different VT frequencies: $25 \mathrm{~Hz}(12,13) ; 26 \mathrm{~Hz}(2,14) ; 30 \mathrm{~Hz}$ $(15,16) ; 35 \mathrm{~Hz}(17,18) ; 40 \mathrm{~Hz}(10,12,13)$; and $45 \mathrm{~Hz}(12$, 13). However, no agreement was found on determining the optimal frequency in the recent publications $(17,19)$. The variability of the protocols showed the inconsistency in the published results of the studies (20). It is therefore important to do research, focusing on finding the optimal combination of these variables to achieve improved muscle performance.

Some studies measured amplitude $(\mathrm{g})$ by attaching an accelerometer to vibrating plates $(3,21)$, or on the body part exposed to vibration (22). Torvinen et al. (23) reported an improvement in the muscle strength after a single 4-minute bout of VT ( $\mathrm{f}=15-30 \mathrm{~Hz}, \mathrm{~A}=3.5-14 \mathrm{~g}$ ). Delecluse et al. (3), reported an increase in the EMG rms for the gastrocnemius and rectus femoris muscles after giving VT $(\mathrm{f}=35-40 \mathrm{~Hz}, \mathrm{~A}=2.28-5.09 \mathrm{~g})$. Tankisheva et al. (24) showed the increase in EMG activity in leg and hip muscles after VT ( $\mathrm{f}=30-50 \mathrm{~Hz}, \mathrm{~A}=0.33-7.98 \mathrm{~g})$. However, Luo et al. (25), concluded that there was no optimal range of training, which may be recommended.

The duration of exposure is also another important factor for VT affecting the muscle response. Increased muscle fatigue was reported with increased duration of exposure $(2,26)$. However, the increased muscle fatigue was reported when exposure was prolonged over time, with a decrease in the EMG activity (27). Bazett-Jones et al. (28) recommended that a short duration of exposure may elicit increased potentiation of neurons (post-activation potentiation (PAP)) and prolonged stimulus, which would lead to fatigue in muscles. Correspondingly, if the stimulus is not sufficient to produce a PAP, neuromuscular activation will not occur significantly $(25,29)$. Therefore, the studies that showed the positive effects of a short duration of exposure did not exceed 10 minutes of total exposure, divided in increments of 30 to 90 seconds $(10,20,28)$.

However, no research has examined the effect of the combination of the frequency, amplitude, duration of exposure, and the days of training on the NP using the vibration plate to deliver VT. Therefore, the present study was designed to identify the effects of the various VT protocols on the MVC grip strength, grip endurance time and the performance of forearm muscles (in terms of EMG activities).

\section{METHODS}

\section{Design of Experiment}

The different combinations of the frequency level of vibration $(35$ and $45 \mathrm{~Hz})(12,13,17,18)$, amplitude $(3 \pm 0.5 \mathrm{~g}$ and $9 \pm 0.5 \mathrm{~g})(23,24)$, and exposure duration $(30$ and 60 seconds) $(10,20,28)$ were classified into the different VT protocols (table I). There were eight different VT protocols, which were given to the participants for 4 days. The training days (4 days) were chosen on the basis of the pilot

Table I. Characteristics of VT parameters and the anthropometric measurements of the participants.

\begin{tabular}{|c|c|c|c|c|c|c|c|c|c|}
\hline \multirow{2}{*}{$\begin{array}{l}\overline{8} \\
0 \\
0 \\
0 \\
0 \\
0 \\
0\end{array}$} & \multirow{2}{*}{ 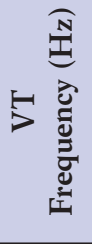 } & \multirow{2}{*}{ 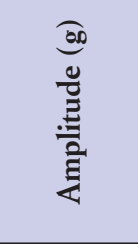 } & \multirow{2}{*}{ 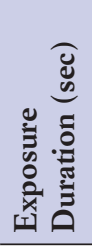 } & \multicolumn{3}{|c|}{ SL Group (Mean \pm SD) } & \multicolumn{3}{|c|}{ CW Group (Mean \pm SD) } \\
\hline & & & & Age (years) & Weight (kg) & Height (cm) & Age (years) & Weight (kg) & Height $(\mathrm{cm})$ \\
\hline A & 35 & $3 \pm 0.5 \mathrm{~g}$ & 30 & $25.6 \pm 5.7$ & $64.4 \pm 15.5$ & $175.4 \pm 5.4$ & $29.6 \pm 11.9$ & $61.9 \pm 7.9$ & $164.3 \pm 4.7$ \\
\hline $\mathrm{B}$ & 35 & $3 \pm 0.5 \mathrm{~g}$ & 60 & $26.7 \pm 6.4$ & $69.7 \pm 15.7$ & $169.1 \pm 4.9$ & $39.7 \pm 14.1$ & $55.3 \pm 4.8$ & $160.1 \pm 3.7$ \\
\hline $\mathrm{C}$ & 35 & $9 \pm 0.5 \mathrm{~g}$ & 30 & $30.6 \pm 1.9$ & $73.1 \pm 4.4$ & $171.8 \pm 4.3$ & $31.4 \pm 10.3$ & $57.3 \pm 3.1$ & $161.1 \pm 4.4$ \\
\hline $\mathrm{D}$ & 35 & $9 \pm 0.5 \mathrm{~g}$ & 60 & $27.4 \pm 7.5$ & $71.6 \pm 18.6$ & $174.4 \pm 5.1$ & $28.6 \pm 7.1$ & $56.6 \pm 8.1$ & $162.6 \pm 4.8$ \\
\hline$E$ & 45 & $3 \pm 0.5 \mathrm{~g}$ & 30 & $28.6 \pm 2.9$ & $71.7 \pm 3.6$ & $172.1 \pm 5.1$ & $21.9 \pm 3.8$ & $64.6 \pm 1.7$ & $169.6 \pm 7.7$ \\
\hline $\mathrm{F}$ & 45 & $3 \pm 0.5 \mathrm{~g}$ & 60 & $34.6 \pm 3.7$ & $69.8 \pm 5.1$ & $172.6 \pm 6.8$ & $23.4 \pm 2.2$ & $56.7 \pm 5.4$ & $160.9 \pm 6.2$ \\
\hline G & 45 & $9 \pm 0.5 \mathrm{~g}$ & 30 & $24.1 \pm 3.9$ & $64.3 \pm 10.9$ & $167.3 \pm 5.3$ & $24.3 \pm 6.2$ & $56.7 \pm 4.1$ & $162.2 \pm 2.5$ \\
\hline $\mathrm{H}$ & 45 & $9 \pm 0.5 \mathrm{~g}$ & 60 & $30.8 \pm 4.8$ & $75.1 \pm 5.1$ & $177.9 \pm 1.7$ & $30.1 \pm 5.3$ & $73.3 \pm 7.8$ & $163.4 \pm 2.6$ \\
\hline
\end{tabular}

In each VT protocol, 7 persons were recruited for the muscle training program. 
run, which showed that most of the improvements were observed on day 4 of the VT. The changes due to the intervention of VT were evaluated by measuring the MVC grip strength, the grip endurance time at 50\% MVC (before and after VT interventions) and the EMG activities of forearm muscles, viz., flexor digitorum superficialis (FDS); flexor carpi ulnaris (FCU); extensor carpi radialis brevis (ECRB); and extensor carpi ulnaris (ECU) in supine posture.

\section{Participants}

The participants were chosen from two sources into two groups of fifty-six persons each: a group of persons having sedentary lifestyle (SL), and another group of construction workers (CW). Only those were chosen who did not report any history of dysfunction of the hand, wrist or forearm, or any other neuromuscular problem such as musculoskeletal disorders, muscular dystrophy, and spinal muscular atrophy. The sedentary lifestyle participants (staff/university students) were called from the campus by notices. The group of construction workers were recruited from a construction site and were paid in cash. The experimental protocol was explained to each participant prior to the experiment. All participants gave their written consent and were allowed to terminate the experiment at any stage. The protocol of the experiment was approved by the ethics committee of the Department (ref. no. EC/60/2017). The basic anthropometric measurements of the participants are presented in table $\mathbf{I}$.

\section{Experimental Rig}

A spring-loaded vibrating plate was designed to support the forearm in supine posture (figure 1) for the vibration exposure. The vibrator (model: Max JS113, brand: M/s Manipol Massager Medicare Products Inc. India) was attached in the center underneath the vibrating plate consisting of a small DC motor with an eccentric head. That was encased in a metal housing and whose frequency was between $15-65 \mathrm{~Hz}$. The eccentric mass of different diameters has also been designed and made to provide the desired combinations of frequency and amplitude.

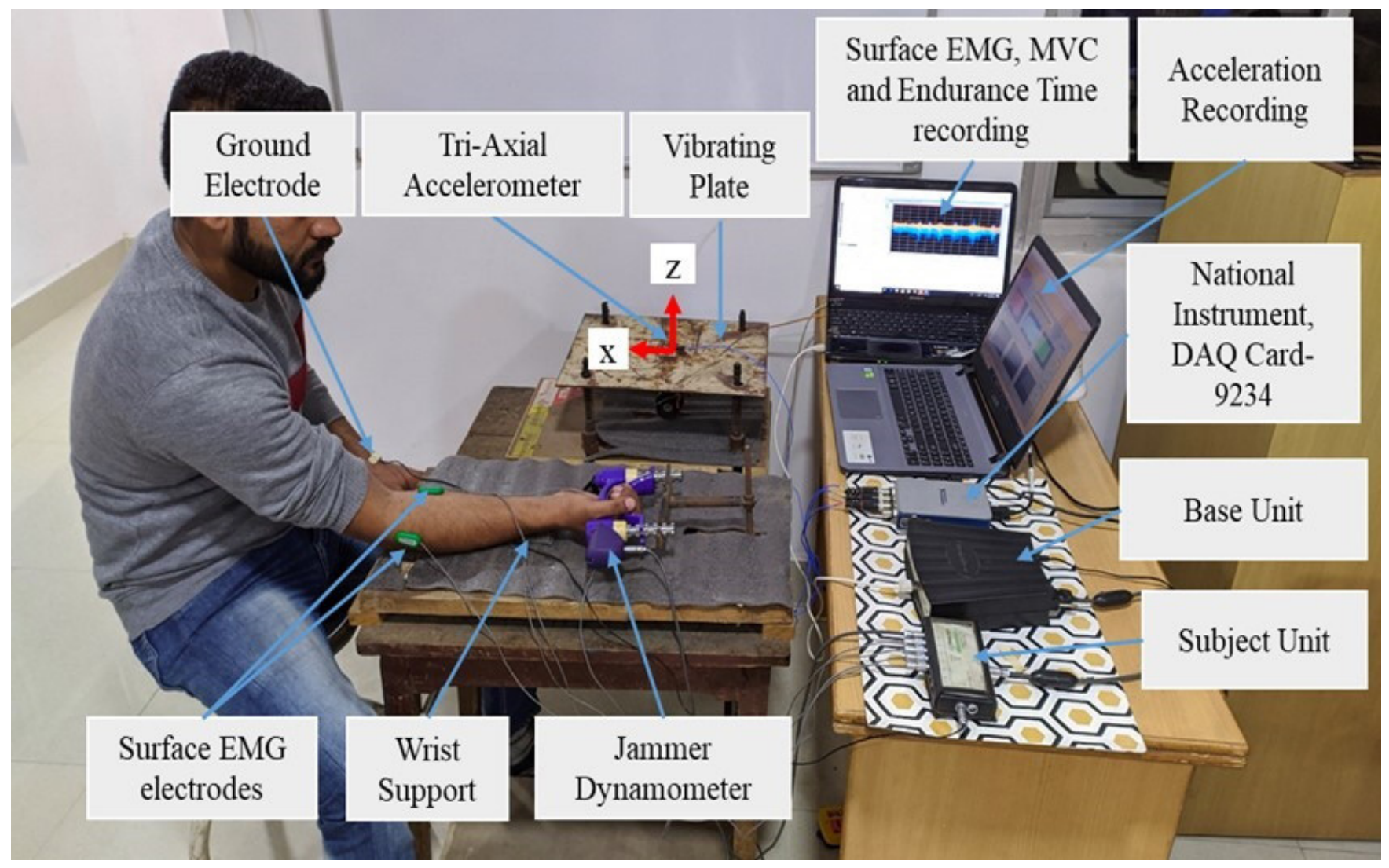

Figure 1. Experimental setup for recording the dependent variables. 


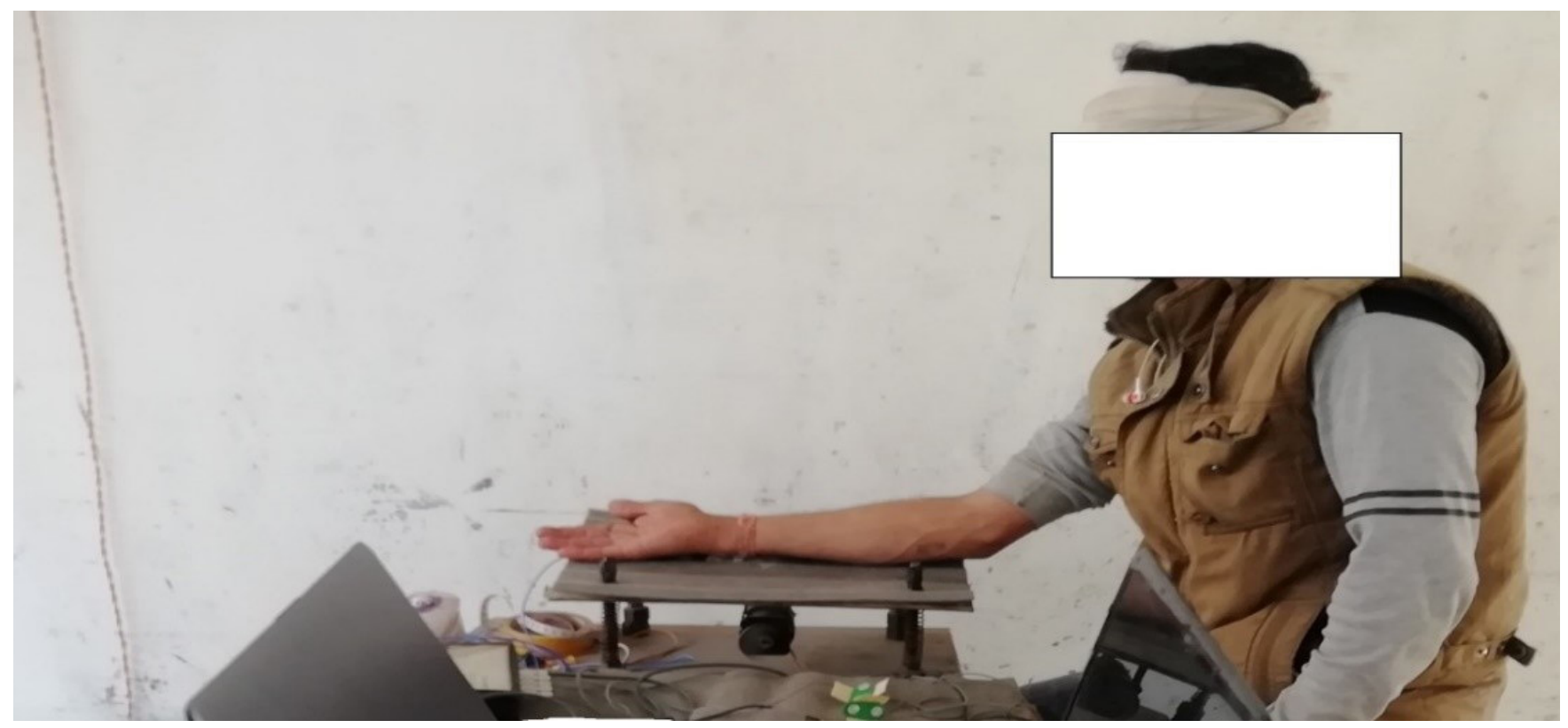

Figure 2. Forearm placed in supine posture on the spring loaded vibrating plate to deliver VT.

\section{Protocol and procedure for the experiment}

To give VT, participants were asked to sit on a height-adjustable chair with the supine forearm posture supported horizontally on the wooden platform with an adjustable wrist support (figure 1) for MVC recording and on a vibrating plate during VT (figure 2). The height of the chair was adjusted so that the participant's right arm was in the coronal plane with a $0^{\circ}$ abduction ensuring an elbow angle of $90^{\circ}-120^{\circ}$.

The following steps were followed to give VT and for the measurements:

1. Identifying the muscles for placement of EMG sensors.

2. Attaching the EMG sensors to the selected muscles and asking the participants to squeeze the grip meter (twice, with a 2 -minute rest period to record the MVC), in supine posture before vibration exposure (BVE) with a fixed grip span along with the EMG recordings.

3. After 5 minutes of rest measuring the grip endurance time at 50\% MVC (taking reference as maximum value of both trials) along with the EMG recordings.

4. The detaching of the EMG sensors and the grip meter.

5. Applying four bouts of VT as per the VT protocols with a rest of 60 seconds after each bout (see table $\mathbf{I}$ ).

6. A rest period of 15 minutes.

7. Repeat point No. 2.

8. Repeat point No. 3 .

9. The detaching of EMG sensors and the grip meter.

10. Repeat point No. 1 to 9 for 4 days to give same VT protocol and on $5^{\text {th }}$ day repeat point No. 2 to 4 .

\section{MVC grip strength and grip endurance time recording}

The participants were asked to squeeze the grip dynamometer to maximum capacity $(30,31)$ until they feel intolerable discomfort and cannot maintain the effort at the desired level. The grip Jammer (Model: G100; Make: M/s Biometrics Ltd. UK) was directly interfaced with 8 channel participant unit Data LINK (DLK900: No. M11138 200909) using cable H2000 (Make: Biometrics Ltd. UK) and connected with the laptop through USB1800 connecting lead. Then the endurance time was recorded at 50\% MVC and simultaneously the EMG signals were obtained using Data LINK for subsequent analyzes.

\section{Surface EMG recording and analyses}

Active differential surface EMG electrodes (SX230, M/s Biometrics Ltd. UK) with center-to-center distance of 20 $\mathrm{mm}$ were used to record the EMG signals at a sampling frequency of $1024 \mathrm{~Hz}$. The pre-amplified EMG signal was transferred to the laptop via Data Link via a R7000 cable, then transferred to the base unit, and then via a connection USB1800 cable (Biometrics Ltd. UK) (32). The reference electrode was attached to the wrist of the non-dominant hand. The electrodes were placed on flexor carpi ulnaris (FCU), flexor digitorum superficialis (FDS), extensor carpi radialis brevis (ECRB), and extensor carpi ulnaris (ECU) muscles of the right forearm $(33,34)$. These muscles 
were selected based on functional importance in gripping (34). Prior to placement of the electrodes, the skin and electrodes were cleaned with a cotton swab soaked in alcohol (35). The EMG data was recorded and analyzed in line with the previous in-house study (32). Further, EMG-rms values were then normalized (nRMS) and presented as a percentage of maximum voluntary exertion (MVE) using maximum dynamic normalization (36).

\section{Recording of vibration levels}

To measure the vibration level, a tri-axial accelerometer (model: SEN041F, manufacturer: piezo-electronic PCB, New York, USA) was mounted in the center of the vibrating plate (figure 1). The vibration levels (g) were acquired via a data acquisition card (National Instrument, DAQ Card-9234), interfaced with a laptop using a LabVIEW12.0 code developed to acquire, record, and analyze the vibration signal.

\section{Feature extraction}

The EMG features listed in table II were used to evaluate NP using EMG signals as were used earlier (37). A LABVIEW 12.0 vi was coded to extract the EMG features.

\section{Formula for Neuromuscular efficiency $\left(\boldsymbol{\eta}_{\mathrm{NME}}\right)$}

Neuromuscular efficiency $\left(\eta_{\mathrm{NME}}\right)$ propose-d by MilnerBrown et al. (38) was modified and a new approach was introduced in an in-house study (39) in which 'endurance time' was taken into account: as a ratio (force * endurance time)/IEMG\}. The effort was calculated according to the force exerted over the endurance time and effort of muscle was calculated according to the integration of EMG signal over endurance time. In addition, the modified formula for evaluating the NP in terms of the \% increase in NME was introduced as below:

$\%$ increase $\eta_{N M E}=\frac{\frac{F_{\text {after }} \times \text { Time }_{\text {after }}}{I E M G_{\text {after }}}-\frac{F_{\text {before }} \times \text { Time }_{\text {before }}}{I E M G_{\text {before }}}}{\frac{F_{\text {before }} \times \text { Time }_{\text {before }}}{I E M G_{\text {before }}}} \times 100$

Where: $\eta_{N M E-}$ neuromuscular efficiency, $F_{\text {after }}{ }^{-}$maximum force at $50 \%$ MVC after day 4 of exposure, $F_{\text {before }}^{\text {after }}$ - maximum force at $50 \%$ MVC after day 1 of exposure Time after $^{-}$endurance time after day 4 of exposure, Time ${ }_{\text {before }}$ - endurance time after day 1 of exposure, IEMG $G_{\text {after }}$ IEMG value of EMG signal after day 4 of exposure, IEMG $G_{\text {before }}$ IEMG value of EMG signal after day 1 of exposure.

\section{RESULTS}

MANOVA were performed using IBM SPSS version 20.0 (table III) on the data to see the effects of VT protocols and days of exposure on MVC grip strength, grip endurance time, neuromuscular efficiency, and EMG features considering as dependent variables.

\section{MVC grip strength and grip endurance time}

The days of exposure and VT protocols had a significant effect on the MVC grip strength and grip endurance time ( $\mathrm{p}$ $<0.001$ ) in both groups (table III). In the post-MANOVA tests, the most of the improvements were observed on days

Table II. Representation of EMG features.

\begin{tabular}{llll}
\hline S. No & EMG Features & Formula & Explanation \\
1. & Integrated EMG (IEMG). & $\sum_{i=1}^{N}\left|x_{i}\right|$ & $\begin{array}{l}\text { Used as identifying index in EMG non-pattern } \\
\text { recognition. }\end{array}$ \\
\hline 2. & Root mean square (RMS). & $\sqrt{\frac{1}{N} \sum_{i=1}^{N} x_{i}^{2}}$ & $\begin{array}{l}\text { Most common feature used during analysis of the } \\
\text { EMG signal. }\end{array}$ \\
\hline 3. & Total Power (TP). & Also called as zero spectral moment (SM0) and energy. \\
\hline 4. & $\begin{array}{l}M \\
\text { Slope based on regression line of } \\
\text { median frequency (SMDF). }\end{array}$ & $\begin{array}{l}\mathrm{Y}=\mathrm{mx}+\mathrm{c} \\
\mathrm{m} \text { is the slope of the line. }\end{array}$ & Used as an index to measure fatigue in muscles fibers. \\
\hline
\end{tabular}

$x i$ denotes the surface EMG signal in a segment $i$ and $\mathrm{N}$ represents length of the sEMG signal, $f j$ is frequency of the spectrum at frequency bin $\mathrm{j}, \mathrm{P}_{\mathrm{j}}$ is the EMG power spectrum at frequency bin $\mathrm{j}$, and $\mathrm{M}$ is length of the frequency bin. 
4 and 5 using Student-Newman-Keuls (SNK) test in both groups. In addition, SNK tests showed that VT protocol C in SL and VT protocol E in CW were highly significant for grip strength and VT protocol B in SL and VT protocol D in $\mathrm{CW}$ were significantly different for endurance.

Figures 3 and $\mathbf{4}$ showed that there was an increase in MVC grip strength and the grip endurance time for both groups on day 4 after VT and on day 5 BVE compared to BVE on day 1 . In addition, the maximum increase in the MVC grip strength was found for VT protocol C (79.757 kgf) in SL and VT protocol E (81.871 kgf) in CW and the maximum increase in grip endurance time was found for VT protocol H (85.916 seconds) in SL and VT protocol B (90.269 seconds) in CW after day 4 of VT.

\section{Neuromuscular Efficiency (NME)}

The days of exposure and VT protocols had a significantly effect on the NME of all muscles $(p<0.001)$ (table III) in both groups. In the post-MANOVA tests, the most of the improvements were observed on days 4 and 5 (SNK) in both groups. In addition, SNK tests showed that VT proto- cols B, E and F for FDS, VT protocols B, D, F and G for FCU, VT protocols $\mathrm{C}$ and D for ECRB and VT protocol D for ECU were significantly different in SL for NME. Also, VT protocols $\mathrm{G}$ and $\mathrm{H}$ for FDS, VT protocol B for FCU and ECRB and VT protocol G for ECU were significantly different in CW for NME.

Figures 5 and $\mathbf{6}$ showed an increase in NME for both groups on day 4 after VT and on day 5 BVE compared to day $1 \mathrm{BVE}$ in all muscles. In addition, the highest increase was found in FDS for VT protocol E $(85.77 \%)$ in SL and VT protocol H (212.8\%) in CW. Additionally, largest \%increase in NME was in ECRB for VT protocol $\mathrm{H}$ $(184.19 \%)$ in SL and FDS for VT protocol G $(195.69 \%)$ in $\mathrm{CW}$ compared to fourth day after VT with BVE on day 1.

\section{Features of the EMG signals}

The days of exposure and VT protocols had a significant effect on the \%normalized EMG rms of all muscles (p $<0.05)$ (table III) in both groups. In the post-MANOVA tests, the most of the improvements were observed on day 4 (SNK) in both groups. In addition, SNK tests

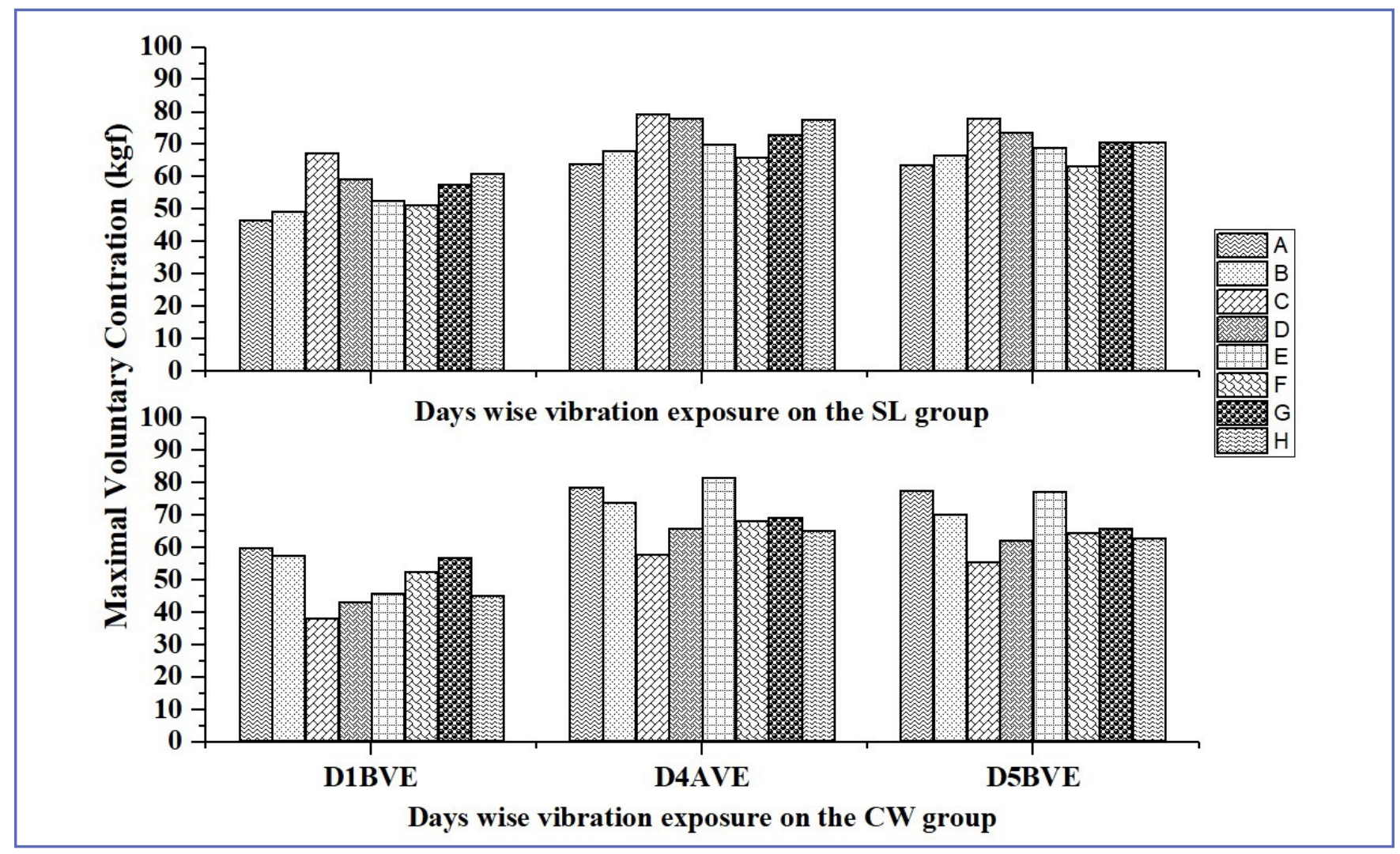

Figure 3. The maximal voluntary contraction values for both groups with respect to VT protocols. 


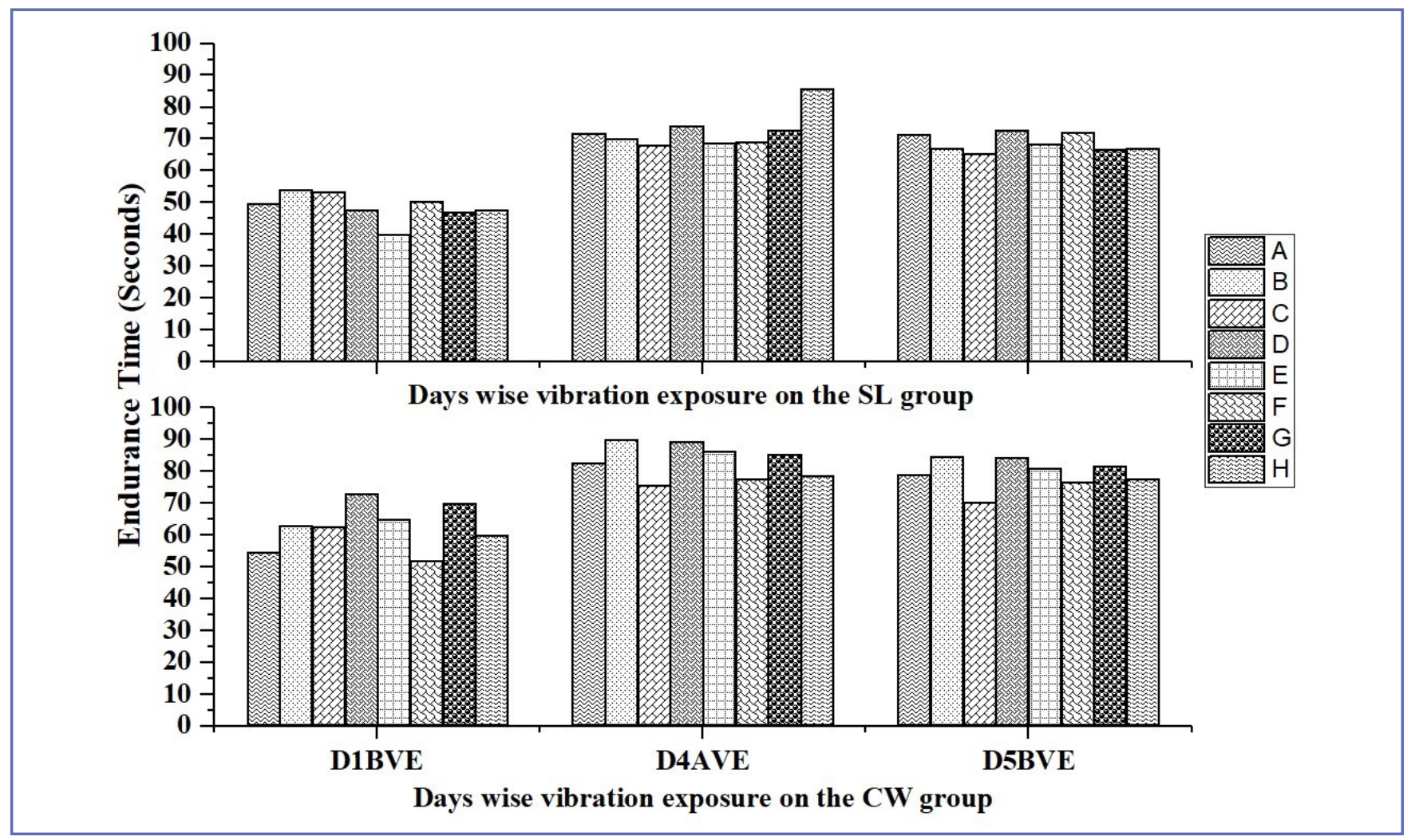

Figure 4. The endurance time values for both groups with respect to VT protocols.

showed that VT protocol F for FDS, VT protocol A for FCU and VT protocol C for ECRB and ECU in SL; and VT protocol $\mathrm{H}$ for FDS and VT protocol C for FCU, ECRB and ECU in CW were significantly different for the \% normalized EMG rms. The significant differences were found in the interaction effect of VT protocols and days of exposure for \% normalized EMG rms in FDS ( $\mathrm{p}=$ $0.012)$ and FCU ( $p=0.004)$ in SL and ECRB ( $p=0.003)$ in CW group.

Figures $\mathbf{7}$ and $\mathbf{8}$ showed an increasing pattern in \% normalized EMG rms in both groups on day 4 after VT and on day 5 BVE compared to day $1 \mathrm{BVE}$ in all the muscles. In addition, the highest increase in \% normalized EMG rms was reported for FDS (40.99\%) for VT protocol F and $36.14 \%$ for VT protocol H in SL and CW group respectively after day 4 of VT.

The days of exposure had a significant effect on the SMDF in FCU, ECRB and ECU $(\mathrm{p}<0.001)$ (table III) in CW group only. In addition, VT protocols had a significant effect on the SMDF in all muscles $(p<0.05)$ in both group (except in FDS for the CW group). The significant differences were found in the interaction effect of VT protocols and days of exposure for SMDF in FDS and FCU $(\mathrm{p}<$ $0.001)$ in SL and FCU ( $p=0.036)$ and ECU $(\mathrm{p}=0.028)$ in $\mathrm{CW}$. Additionally, SNK tests showed that VT protocol D for FDS and ECU, VT protocol E for FCU and VT protocol $\mathrm{H}$ for ECRB in SL, and VT protocol $\mathrm{H}$ for FCU, VT protocol D for ECRB and VT protocol $\mathrm{E}$ for ECU in CW were significantly different for SMDF.

Figures $\mathbf{9}$ and $\mathbf{1 0}$ showed an increase in SMDF pattern for all VT protocols in most of the muscles after VT on day 4 compared to day 1 BVE in both groups. In addition, the highest slope was found in ECRB for most of the VT protocols. Interestingly, there was a decline in SMDF pattern in most of the muscles after 5 days of exposure in all VT protocols compared to day 1 BVE in both groups. In addition, VT protocols had a significant effect on the integrated EMG (IEMG) activity in all muscles $(\mathrm{p}<0.001)$ in both groups (except in ECRB for SL) (table III). In addition, VT protocol C for FDS, FCU, and ECU in SL and VT protocol D for FDS and ECU, VT protocol E for FCU and VT protocol $G$ for ECRB in CW were significantly different (SNK) for IEMG. Additionally, there was an increasing pattern in IEMG values in both groups after day 4 of VT 


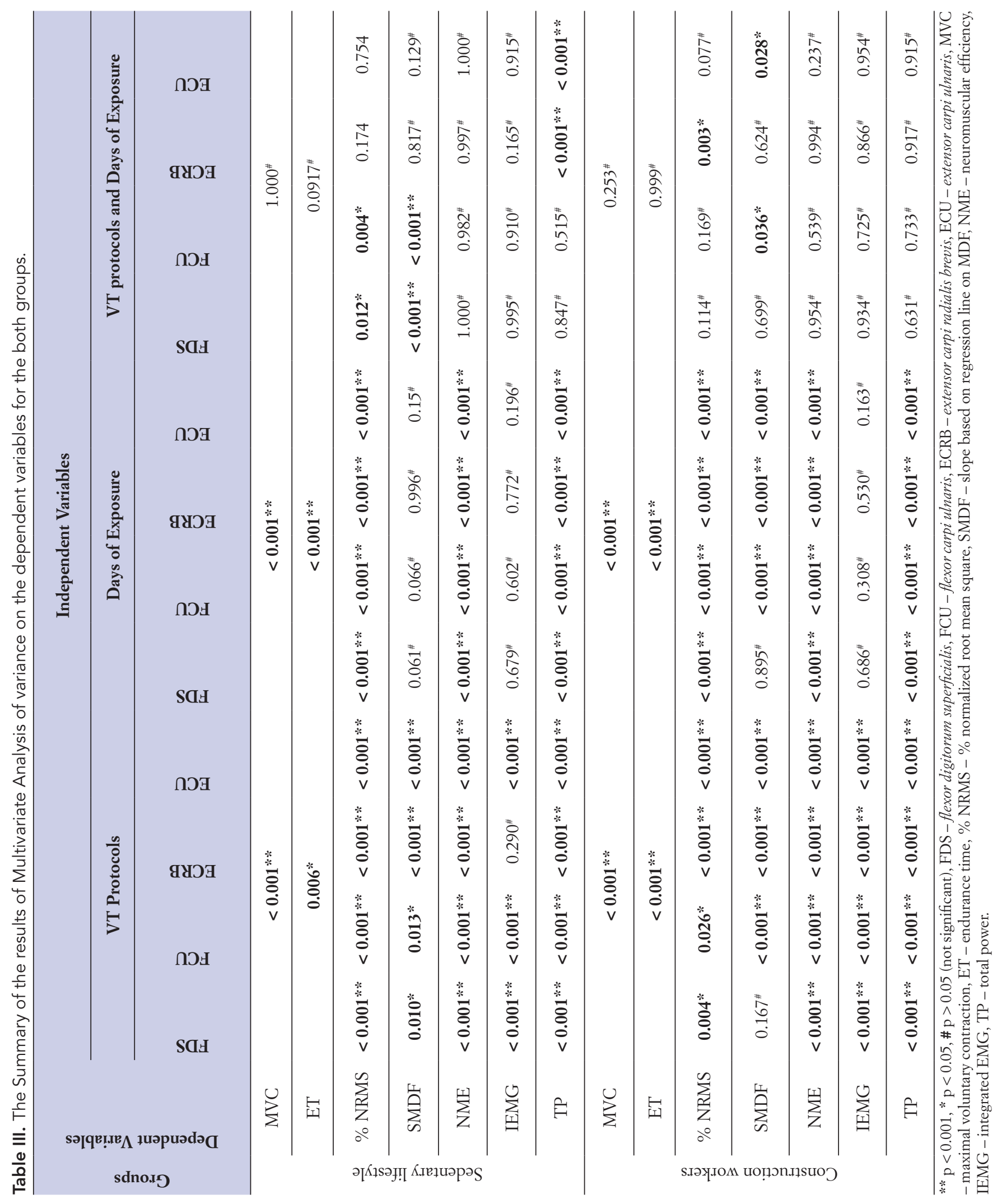




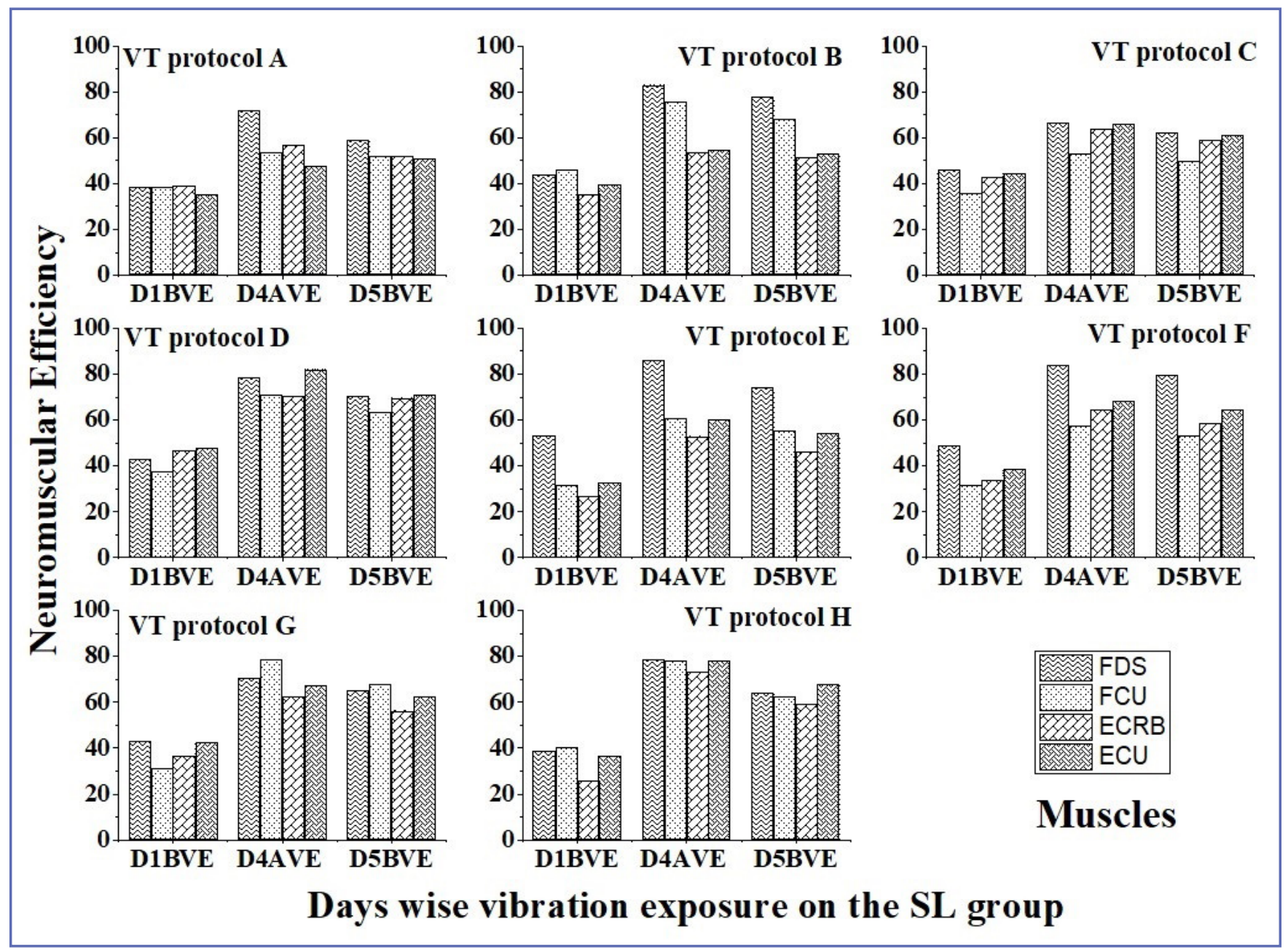

Figure 5. The NME values for the SL group in all muscles with respect to VT protocols.

and on day 5 BVE in most of the muscles and VT protocols compared to day $1 \mathrm{BVE}$.

The days of exposure and VT protocols had a significant effect on total power (TP) of all muscles $(\mathrm{p}<0.001)$ (table III) in both groups. In the post-MANOVA tests, the most of the improvements were observed on days 4 and 5 (SNK) for TP. In addition, VT protocol $\mathrm{H}$ for FDS and ECU, VT protocol C for FCU, and VT protocol A for ECRB in SL and VT protocol E for FDS, VT protocol D for FCU and ECU and VT protocol F for ECRB in CW were significantly different (SNK) for TP. The significant differences were found in the interaction effect of VT protocols and days of exposure for TP in ECRB and ECU $(\mathrm{p}<0.001)$ in SL only. In addition, FCU exhibited the greatest increase in TP for VT protocol C in SL and in ECRB in all VT protocols in $\mathrm{CW}$ after day 4 of VT. The TP value also increased in most of the muscles and VT protocols on day 5 BVE compared to day 1 BVE in both groups.

\section{DISCUSSION}

\section{MVC grip strength and grip endurance time}

In line with present results, several studies have reported an increase in the grip strength using different frequencies of VT $(12,13,17,18,23)$. However, Baudry et al. (40) reported a decrease in the grip strength of older participants compared to younger participants; the similar trend was also found in the present study. The MVC grip strength was highest for VT protocol $\mathrm{E}$ in $\mathrm{CW}$ with younger age group $(21.9 \pm 3.8$ years $)$. In addition, the grip endurance of the abdominal and upper body muscles 


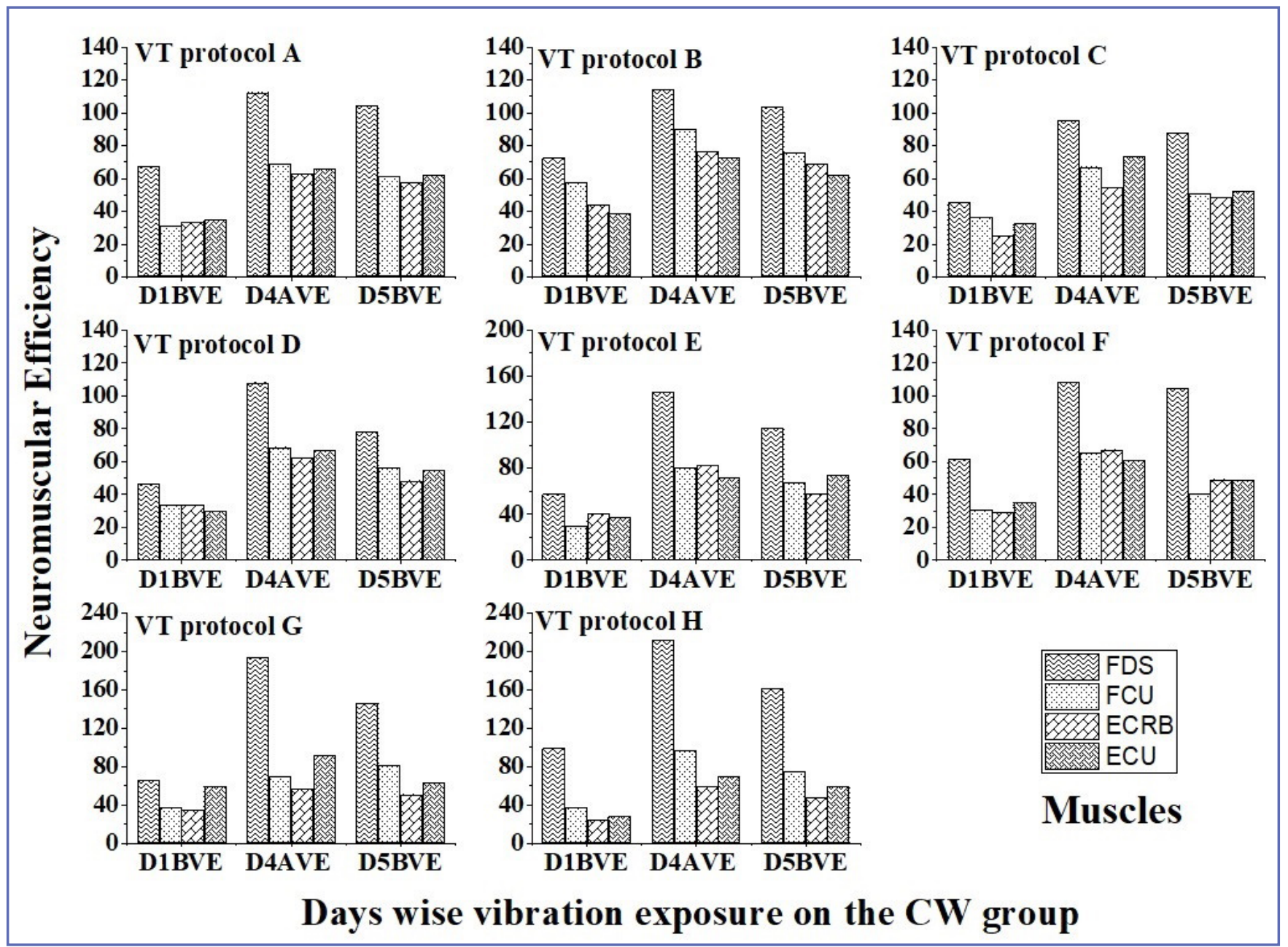

Figure 6. The NME values for the CW group in all muscles with respect to VT protocols.

improved after VT in sedentary individuals $(3,41)$ as was also reported in the present study. However, Samuelson et al. (42), reported a significant reduction in grip endurance after VT. In addition, Hunter et al. (43) found higher grip endurance for older participants than for younger participants. In the present results, it was also found that older participants (CW group) $(39.7 \pm 14.1$ years $)$ had a longer endurance (VT protocol B) than the younger age group (VT protocol E).

\section{Neuromuscular Efficiency}

Milner-Brown et al. (38) used the term neuromuscular efficiency (NME) to quantify the changes in NP over time based on the Force/IEMG ratio at 50\% MVC. However, Milner-Brown et al. (38) showed a decrease in the NME of the flexor muscles $(49 \pm 15 \%)$. In addition, Alam et al. (39) found more than $50 \%$ increase in neuromuscular performance was after giving VT at $35 \mathrm{~Hz}$. Neuromuscular adaptation following high-frequency, low-amplitude 5-week VT training was investigated and revealed no significant improvement in NME through modulation of muscle spindle sensitivity (19). In another study (44), significant improvement in NME was reported; however, they reported no significant difference in maximal strength and EMG amplitude before and after the intervention $(\mathrm{p}>0.3)$. The NME of the abdominal muscles differed with age, always higher in the elderly (45). Interestingly, in the present study also, age had a significant effect on NME. The elders in the group of construction workers for VT protocol H $(212.8 \%$ in FDS) reported higher NME as compared to younger in the $\mathrm{CW}$ for VT protocol $\mathrm{E}$. 


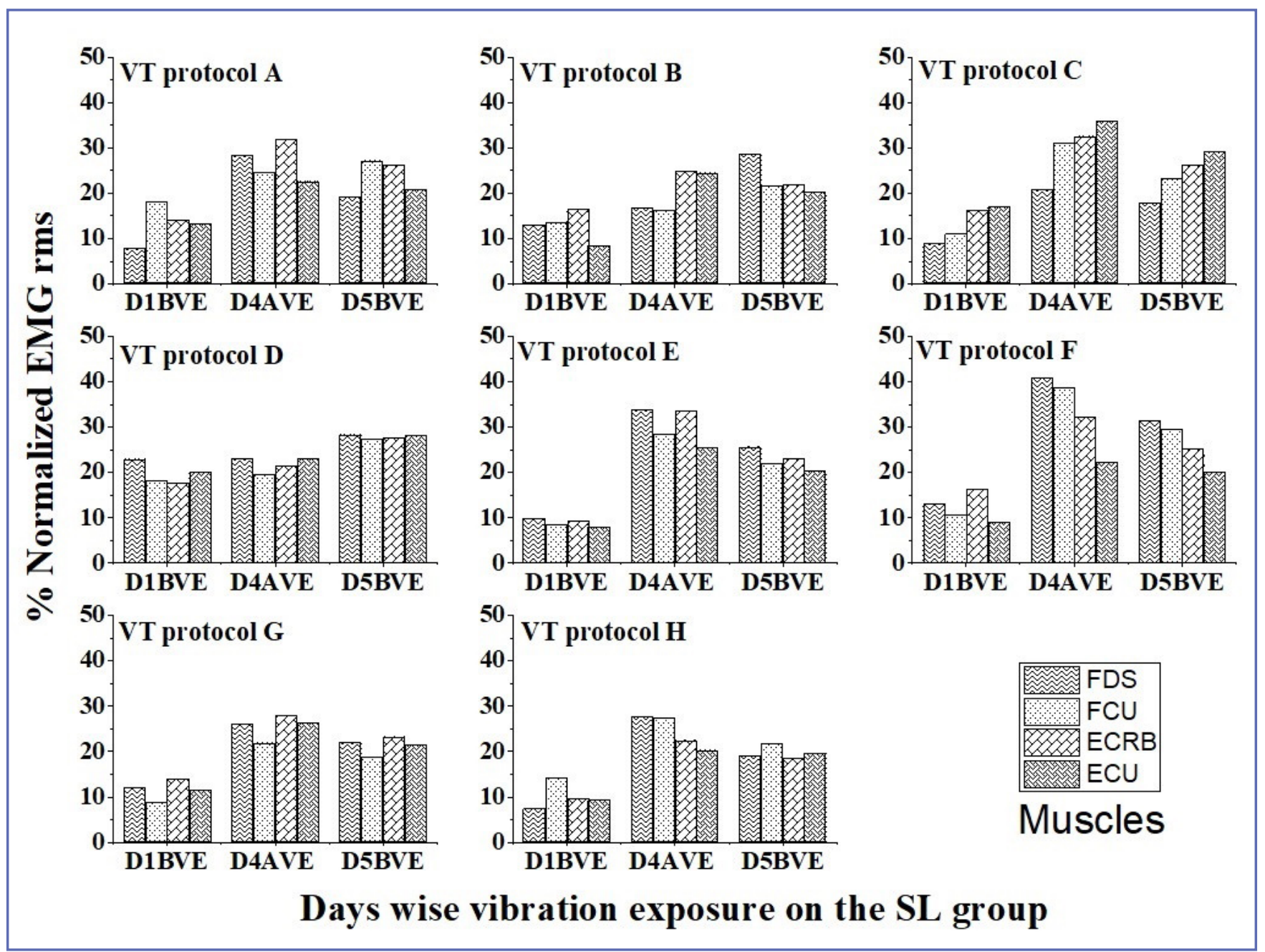

Figure 7. The \% normalized EMG rms values for the SL group in all muscles with respect to VT protocols.

It was also estimated that fatigue-related NME reduction indicated that more MUs were recruited to generate the same strength as non-fatigued muscle. In addition, changes in NME with fatigue and time of day are also attributable to changes in the neural drive $(46,47)$. Interestingly, in the present study based on regression line of median frequency there was more fatigue in extensor muscle (ECRB) for most VT protocols in both groups. Hagg and Milerad (48) also reported that ECRB showed higher fatigue response than FDS and FCU. Therefore, the NME was significantly higher in the flexor muscle (FDS) than in the extensor muscle (ECRB and ECU) in both groups for all VT protocols. In contrary, Alam et al. (39) reported an increase in NME in the performance of ECRB muscle after $35 \mathrm{~Hz}$ of VT and ECU muscle after $23 \mathrm{~Hz}$ of VT. There is an evidence that continuous improvement in the NME is largely responsible for the additional strength gain. In the present study, MVC grip strength and NME were increased for all VT protocols on days 1 to 4 after VT in both groups. Therefore, the main factor of this improvement was that VT can improve the evoked motor potentials (49) as well as the EMG signal (50), signifying the excitability of the motor cortex associated with muscle adaptations (51) and the increased muscle performance, faster muscle activation and better coordination (52). In a study (53), it was shown that higher VT frequency and amplitude ( $\mathrm{f}=50 \mathrm{~Hz}, \mathrm{~A}=2.51 \mathrm{~mm}, \mathrm{a}=98.55$ $\mathrm{m} / \mathrm{s}^{2}$ ) elicits more neuromuscular facilitation than a small VT frequency and amplitude $(\mathrm{f}=30 \mathrm{~Hz}, \mathrm{a}=1.15 \mathrm{~mm}, \mathrm{~A}=$ $20.44 \mathrm{~m} / \mathrm{s}^{2}$ ). Present study also suggested that the combinations of a higher VT frequency $(45 \mathrm{~Hz})$, a higher amplitude $(9 \mathrm{~g} \pm 0.5 \mathrm{~g})$ and a longer exposure time (60 seconds) induced greater neuromuscular efficiency. 


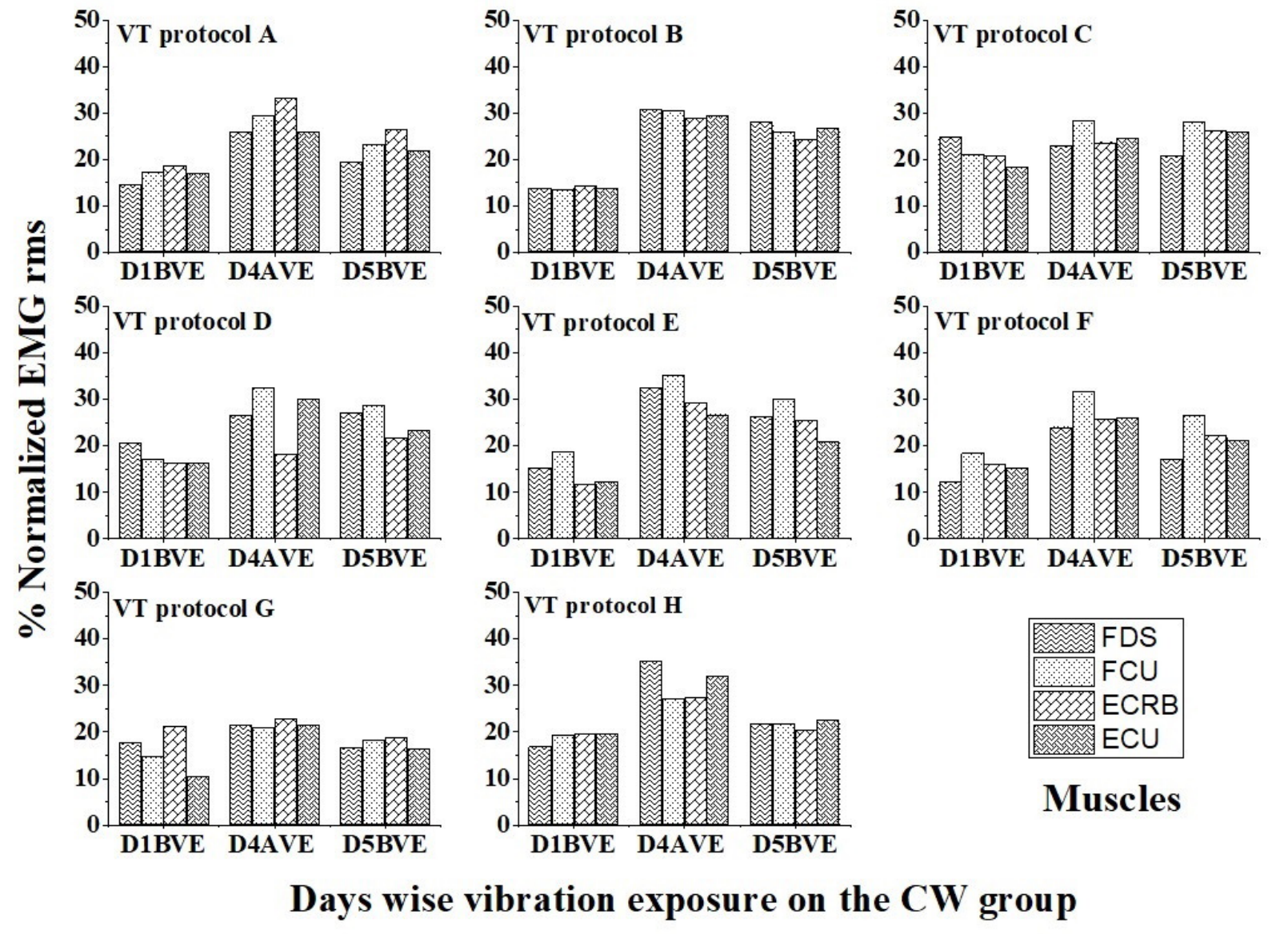

Figure 8. The \% normalized EMG rms values for the CW group in all muscles with respect to VT protocols.

\section{Muscular performance change based on individual features}

The increase in EMG activity is probably attributed to the recruitment of fresh motor units, used to compensate the decline in performance (54). In line with current results, several studies have reported a significant increase in EMG activity after VT $(10,12,55)$; however, several studies showed no significant effect $(13,51,56)$. Hazell et al. (12) reported significantly different effects of VT at $25 \mathrm{~Hz}$ and $30 \mathrm{~Hz}$ and at 40 to $45 \mathrm{~Hz}$ on the \%normalized EMG activity in the vastus lateralis muscle. In another study, no significant difference in the \%normalized EMG rms value between vibration and rest conditions was reported; however, the duration of exposure was not acknowledged (57). Present study also showed, days of exposure and VT protocols had a significant effect on the \% normalized EMG rms of all muscles ( $\mathrm{p}<$ $0.05)$ immediately and after post-treatment in both groups.
Mogk et al. (33) concluded that muscle activation was primarily dependent on forearm posture, with the strongest activation of the supinated flexor muscles $(0.5-6.4 \%$ MVE) and greater extensor muscle activation in pronation (3.5-8.8\% MVE) . In present study, highest \%normalized EMG rms was reported for FDS (40.99\% of MVE) after VT protocol F in SL and 36.14\% of MVE for VT protocol H in CW after VT on day 4. On the contrary, Loren et al. (58) reported that the muscle acivity of the ECRB was greater than that of ECU in the supine posture and Bano et al. (59) reported that ECU was the most active muscle for all supine experimental conditions. Therefore, it may be suggested that the activation of the flexor muscle was greater than that of the activation of the extensor muscle and the combination of a higher frequency with a low amplitude induced a greater activation of muscle EMG activity with a longer duration of exposure. 


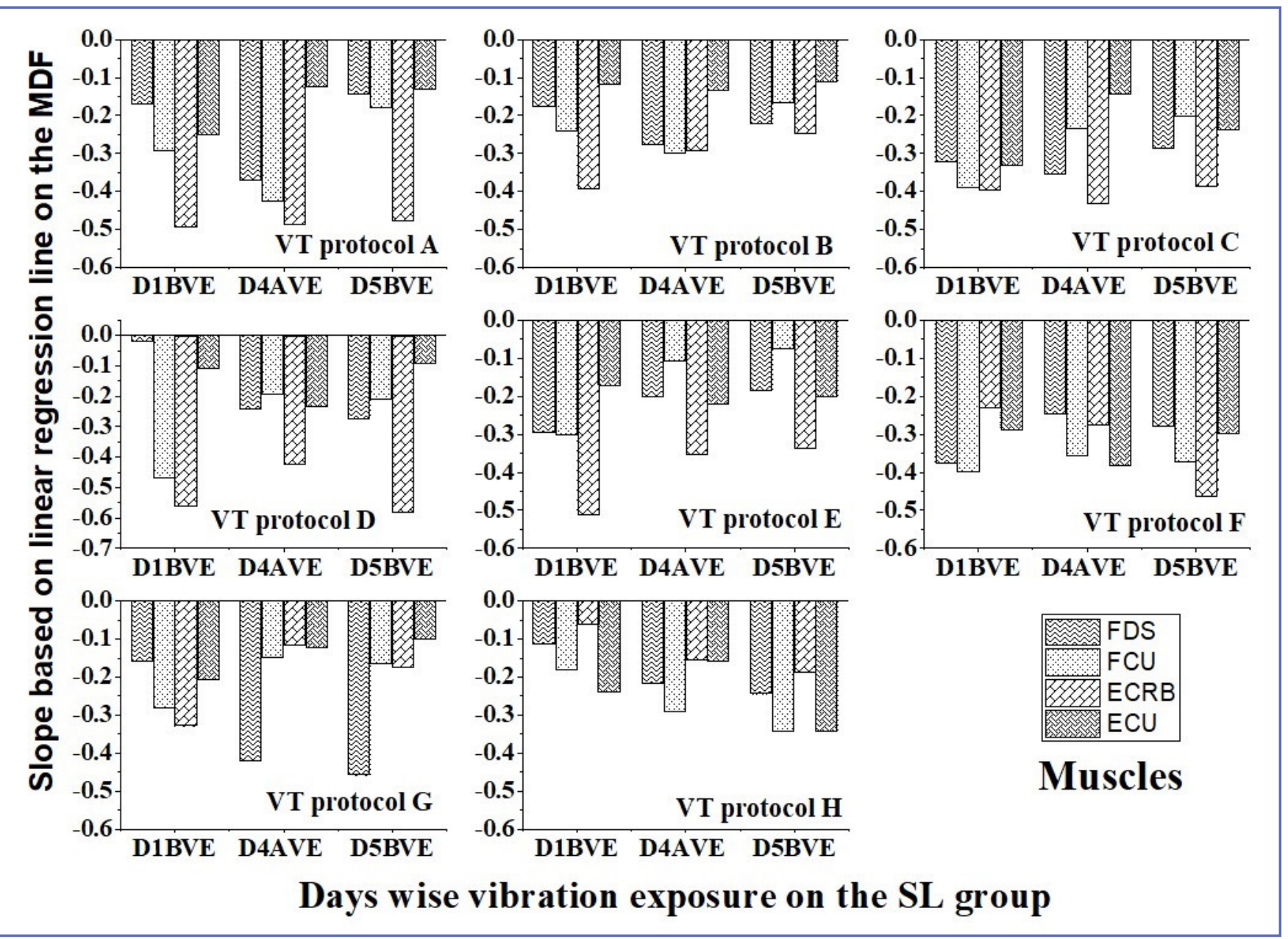

Figure 9. The slope based on linear regression line on median frequency values for the SL group in all muscles with respect to VT protocols.

The present results showed the significantly increased IEMG value in most of the muscles after VT interventions in both groups; these were in line with previous studies (55, 60). In addition, there was significant increase in MVC grip strength after VT. Therefore, it can be suggested that the progressive enhancement in EMG activity (IEMG) during sustained contractions was possibly due to the increased recruitment of MUs as evident in a study (61).

The results showed an increase in TP profile after VT on days 1 to 4 in all muscles in both groups. Consistent with current findings, a significant increase in TP was reported after VT $(51,62,63)$, while some researchers have found little or no effect of VT on upper body power $(56,64)$. However, it has been suggested that a smaller vibration amplitude is needed to activate and optimize the sensitivity of the muscle (64). In contrast, present study showed FCU had greatest increase in TP for VT protocol C in SL with low frequency $(35 \mathrm{~Hz})$, higher amplitude $(9 \mathrm{~g} \pm 0.5 \mathrm{~g})$ and short exposure duration ( 30 seconds) after the VT.

In addition, the difference in the results could be attributed to the use of different vibrating devices, frequencies, duration of exposure, different muscles and difference in the individual response to vibratory stimuli. In addition, current results indicate that prolonged exposure in the same postures during VT protocol may limit muscle relaxation and contribute to fatigue, mainly in the extensor muscles. In addition, the level of muscular effort depends on the grip strength of the individual, which may predispose some to an increased risk of injury to the forearm.

\section{CONCLUSIONS}

After discussion on the results, the following points may be concluded: 


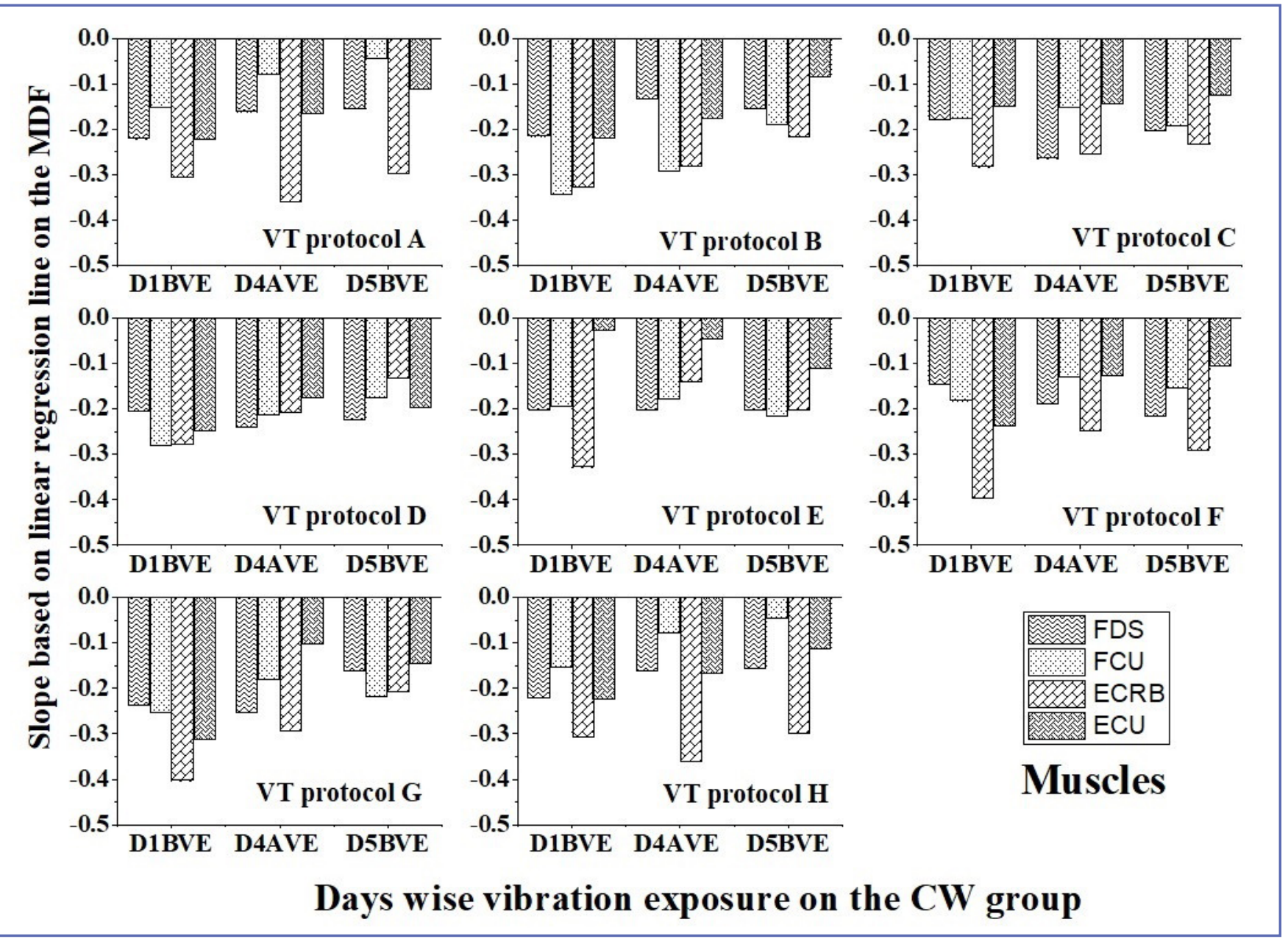

Figure 10. The slope based on linear regression line on median frequency values for the CW group in all muscles with respect to VT protocols.for the CW group in all muscles with respect to VT protocols.

1. Days of exposure and VT protocols had a significant effect on the MVC grip strength and grip endurance time in both groups.

2. The \% normalized EMG rms value increased in most of the muscles and flexor muscle activation was greater than that of extensor muscle activation in both groups.

3. Based on regression line of MDF of EMG signal highest fatigue was reported in ECRB muscle in both groups.

4. NME and TP increased significantly in all muscles with respect to days of exposure and VT protocols in both groups.

\section{A sample guideline for the therapist}

The results may be used to prepare guidelines for VT in rehabilitation, healthcare, sports, medical for therapists (65). As a sample, it can be suggested that if VT was administered at low frequency $(35 \mathrm{~Hz})$, small amplitude $(3 \mathrm{~g} \pm 0.5 \mathrm{~g})$ and longer exposure duration (4 bouts of 60 seconds) increased grip strength is achieved. At higher VT frequency $(45 \mathrm{~Hz})$, low amplitude $(3 \mathrm{~g} \pm 0.5 \mathrm{~g})$, and short exposure time ( 4 bouts of 30 seconds) increased endurance time may be obtained. Aditionally, higher VT frequency $(45 \mathrm{~Hz})$, higher amplitude $(9 \mathrm{~g} \pm 0.5 \mathrm{~g})$ and longer exposure time ( 4 bouts of 60 seconds) induce greater neuromuscular efficiency.

\section{Limitations and Future Scope}

One of the most important limitation of the study may be sample size. A larger sample size of the participants in both groups could give a better and stronger support to the findings of the study. The 'lasting effects' of VT on neuromuscular performance are still questionable. There- 
fore, future studies with a longer training/observation days are needed to provide further understanding of the effects of VT. Further, the reported low level of discomfort was overlooked, which may have inhibited improvement in muscle performance. Another important consideration for future research possibly be to standardize vibration therapy techniques. Future studies are still recommended to suggest more precise identification of different forms of vibration therapies (whole-body and local vibration) for different population groups.

\section{REFERENCES}

1. Cardinale M, Bosco C. The use of vibration as an exercise intervention. Exerc Sport Sci Rev 2003b;31(1):3-7.

2. Rittweger J, Beller G, Felsenberg D. Acute physiological effects of exhaustive whole-body vibration exercise in man. Clin Physiol 2000;20(2):134-142.

3. Delecluse C, Roelants M, Verschueren S. Strength increase after whole-body vibration compared with resistance training. Med Sci Sports Exerc 2003;35(6):1033-1041.

4. Alam MM, Khan AA, Farooq M. Effect of whole-body vibration on neuromuscular performance: A literature review. Work 2018;59(4):571-583.

5. Li W, Li C, Xu Q, Ji L. Effects of Focal Vibration over Upper Limb Muscles on the Activation of Sensorimotor Cortex Network: An EEG Study. J Healthc Eng 2019:1-7.

6. Chisari E, Pavone V, Sessa G, Ravalli S, Musumeci G. Electromyostimulation and whole-body vibration effects in elder sarcopenic patients. MLTJ 2019;9(3):433-441.

7. Salami A, Roostayi MM, Sadat Naimi S, Shadmehr A, Baghban AA. The immediate effects of whole body vibration on cervical joint position sense in subjects with forward head posture. MLTJ 2018;8(2):255-260.

8. Cerciello S, Rossi S, Visonà E, Corona K, Oliva F. Clinical applications of vibration therapy in orthopaedic practice. MLTJ 2016;6(1):147-156.

9. Eklund G, Hagbarth KE. Normal Variability of Tonic Vibration Reflexes in Man. ExpNeurol 1966;16(1):80-92.

10. Cardinale M, Lim J. Electromyography activity of vastus lateralis muscle during whole-body vibrations of different frequencies. J Strength Cond Res 2003a;17(3):621-624.

11. Foti C, Laurini A, Tiberti S, et al. Leg extension test, semg and vibratory stimuli to assess functional recovery following knee joint surgery. MLTJ 2012;2(2):127-132.

12. Hazell TJ, Jakobi JM, Kenno KA. The effects of wholebody vibration on upper- and lower-body EMG during static and dynamic contractions. Appl Physiol Nutr Metab 2007;32(6):1156-1163.

13. Moras G, Rodriguez-Jimenez S, Tous-Fajardo J, Ranz D, Mujika I. A Vibratory bar for upper body: Flexibility and acute effects on EMGrms activity. J Strength Cond Res 2010;28(8):2132-2142.

14. Costantino C, Bertuletti S, Romiti D. Efficacy of Whole-Body Vibration Board Training on Strength in Athletes after Anterior Cruciate Ligament Reconstruction: A Randomized Controlled Study. Clin J Sport Med 2018;28(4):339-349.

\section{ACKNOWLEDGEMENTS}

The author would like to thank the Council of Scientific \& Industrial Research (CSIR), Human Resource Development Group, New Delhi, India, for awarding Senior Research Fellowship (SRF), having Ack. No. 141530/2K15/1, File No. 09/112(0553)2K17-EMR-I.

\section{CONFLICT OF INTERESTS}

The authors declare that they have no conflict of interests.

15. Cormie P, Deane RS, Triplett NT, McBride JM. Acute effects of whole- body vibration on muscles activity, strength, and power. J Strength Cond Res 2006;20(2):257-261.

16. Goebel R, Haddad M, Kleinöder H, Yue Z, Heinen T, Mester J. Does combined strength training and local vibration improve isometric maximum force? A pilot study. MLTJ 2017;7(1):186-191.

17. Di Giminiani R, Masedu F, Tihanyi J, Scrimaglio R, Valenti M. The interaction between body position and vibration frequency on acute response to whole body vibration. J Electromyogr Kinesiol 2013;23(2):245-251.

18. Moawd SA, Abdelhalem NM, Samhan AF, Mahmoud WS. Effects of Whole-Body Vibration and Resistance Training on Muscular Performance in Young Adults. J Am Sci 2014;10(1):67-73.

19. Yeung SS, Yeung EW. A 5-week whole body vibration training improves peak torque performance but has no effect on stretch reflex in healthy adults: a randomized controlled trial. J Sports Med Phys Fitness 2015;55(5):397-404.

20. Cardinale M, Lim J. The acute effects of two different whole body vibration frequencies on vertical jump performance. Medicina dello Sport 2003;56(4):287-292.

21. Di Giminiani R, Tihanyi J, Safar S, Scrimaglio R. The effects of vibration on explosive and reactive strength when applying individualized vibration frequencies. J Sports Sci 2009;27(2):169-177.

22. Abercromby AF, Amonette WE, Layne CS, McFarlin BK, Hinman MR, Palosk WH. Vibration exposure and biodynamic responses during whole-body vibration training. Med Sci Sports Exerc 2007;39(10):1794-1800.

23. Torvinen S, Kannus P, Sievanen H, Jarvinen T, Pasa M, Kontulainen S. Effect of a vibration exposure on muscular performance and body balance. Randomized cross-over study. Clin Physiol Funct Imaging 2002;22(2):145-152.

24. Tankisheva E, Jonkers I, Boonen S, et al. Transmission of whole-body vibration and its effect on muscle activation. J Strength Cond Res 2014;27(9):2533-2541.

25. Luo J, McNamara B, Moran K. The use of vibration training to enhance muscle strength and power. Sports Med 2005;35(1):23-41.

26. Bongiovanni LG, Hagbarth KE, Stjernberg L. Prolonged muscles vibration reducing motor output in maximal voluntary contraction in man. J Physiol 1990;423(1):15-26. 
27. Bongiovanni LG, Hagbarth KE. Tonic vibration reflexes elicited during fatigue from maximal voluntary contractions in man. J Physiol 1990;423(1):1-14.

28. Bazett-Jones DM, Finch HW, Dugan EL. Comparing the effects of various whole-body vibration accelerations on counter- movement jump performance. J Sports Sci Med 2008;7(1):144-150.

29. Bazett-Jones DM, Winchester JB, McBride JM. Effect of potentiation and stretching on maximal force, rate of force development, and range of motion. J Strength Cond Res 2005;19(2):421-426.

30. Alam MM, Khan AA, Farooq M, Bhardwaj S. Effect of One Week Intervention of Vibratory Massage Therapy on Forearm Grip Strength and Endurance. 14th International Conference on Humanizing Work and Work Environment. NIT Jalandhar 2016:91-95.

31. Khan AA, Sullivan LO, Gallwey TJ. Effects of combined wrist flexion/extension and forearm rotation and two levels of relative force on discomfort. Ergonomics 2009;52(10):1265-1275.

32. Farooq M, Khan AA. Effects of shoulder rotation combined with elbow flexion on discomfort and EMG activity of ECRB muscle. Int J Ind Ergon 2014;44(6):882-891.

33. Mogk JPM, Keir PJ. The effects of posture on forearm muscle loading during gripping. Ergonomics 2003;46(9):956-975.

34. Roman-liu D, Bartuzi P. The influence of wrist posture on the time and frequency EMG signal measures of forearm muscles. Gait Posture 2013;37(3):340-344.

35. Delagi EF, Perotto A, Iazzetti J, Morrison D. Anatomical Guide for the Electromyographer. New York: Charles C Thomas, 1980.

36. Strasser H. Electromyography: methods and techniques. International Encyclopaedio of ergonomics and Human factors 2001;3:1801-1804.

37. Phinyomark A, Quaine F, Charbonnier S, Serviere C, Tarpin-Bernard F, Laurillau Y. EMG feature evaluation for improving myoelectric pattern recognition robustness. Expert Syst Appl 2013;40:4832-4840.

38. Milner-Brown H, Mellenthin M, Miller R. Quantifying human muscle strength, endurance and fatigue. Arch Phys Med Rehabil 1986;67(8):530-535.

39. Alam MM, Khan AA, Farooq M. Effects of vibration therapy on neuromuscular efficiency \& features of the EMG signal based on endurance test. J Bodyw Mov Ther 2020;24(4):325-335.

40. Baudry S, Klass M, Pasquet B, Duchateau J. Age-related fatigability of the ankle dorsiflexor muscles during concentric and eccentric contractions. Eur J Appl Physiol 2007;100(5):515-526.

41. Delecluse C, Roelants M, Diels R, Koninckx E, Verschueren S. Effects of whole body vibration training on muscle strength and sprint performance in sprint-trained athletes. Int J Sports Med 2005;26(8):662-668.

42. Samuelson B, Jorfeldt L, Ahlborg B. Influence of vibration on work performance during ergometer cycling. Ups J Med Sci 1989;94(1):73-79.

43. Hunter SK, Critchlow A, Enoka RM. Muscle endurance is greater for old men compared with strength-matched young men. J Appl Physiol 2005;99(3):890-897.

44. Casale R, Boccia G, Symeonidou Z, et al. Neuromuscular efficiency in fibromyalgia is improved by hyperbaric oxygen ther- apy: looking inside muscles by means of surface electromyography. Clin Exp Rheumatol 2019;37(1):75-80.

45. Christoph A, Agnes H, Bernd F. The Neuromuscular Efficiency of Trunk Muscles is altered by Age in the Abdominal Muscles but by Gender in the Back Muscles. Int J Sports Exerc Med 2018;4(2):1-9.

46. Nicolas A, Gauthier A, Bessot N, Moussay S, Davenn D. Time-of-day effects on myoelectric and mechanical properties of muscle during maximal and prolonged isokinetic exercise. Chronobiol Int 2005;22(6):997-1011.

47. Nicolas A, Gauthier A, Trouillet J, Davenne D. The influence of circadian rhythm during a sustained submaximal exercise and on recovery process. J Electromyogr Kinesiol 2008;18(2):284-290.

48. Hagg GM, Milerad E. Forearm extensor and flexor muscle exertion during simulated gripping work-an electromyographic study. Clin Biomech 1997;12(1):39-43.

49. Kossev A, Siggelkow S, Kapels H, Dengler R, Rollnik JD. Crossed effects of muscle vibration on motor-evoked potentials. Clin Neurophysiol 2001;112(3):453-456.

50. Ritzmann R, Kramer A, Gruber M, Gollhofer A, Taube W. EMG activity during whole body vibration: motion artifacts or stretch reflexes? Eur J Appl Physiol 2010;110(1):143-151.

51. Bosco C, Cardinale M, Tsarpela O. Influence of vibration on mechanical power and electromyogram activity in human arm flexor muscles. Eur J Appl Physiol 1999;79(4):306-311.

52. Cressey E, Fitzgerald M. Maximum Strength: Get Your Strongest Body. In: 16 Weeks with the Ultimate Weight-Training Program. Da Capo Lifelong Books, 2008:p 256.

53. Marin PJ, Herrero AJ, Sainz N, Rhea MR, Garcia-Lopez D. Effects of different magnitudes of whole-body vibration on arm muscular performance. J Strength Cond Res 2010;24(9):2506-2511.

54. Felici F, Quaresima V, Fattorini L, Sbriccol P, Filligoi GC, Ferrari M. Biceps brachii myoelectric and oxygenation changes during static and sinusoidal isometric exercises. J Electromyogr Kinesiol 2009;19(2):1-11.

55. Kihlberg S, Attebrant M, Gemne G. Acute effects of vibration from a chipping hammer and a grinder on the hand- arm system. Occup Environ Med 1995;52(11):731-737.

56. Moran K, McNamara B, Luo J. Effect of vibration training in maximal effort (70\% 1RM) dynamic bicep curls. Med Science Sports Exerc 2007;39(3):526-533.

57. Humphries B, Warman G, Purton J, Doyle T. The influence of vibration on muscle activation and rate of force development during maximal isometric contractions. J Sports Sci Med 2004;3(1):16-22.

58. Loren GJ, Shoemaker SD, Burkholder TJ, Jacobson MD, Fride NJ, Lieber RL. Human wrist motors: biomechanical design and application to tendon transfers. J Biomech 1996;29(3):331-342.

59. Bano F, Zulqarnain M, Khan AA. EMG of forearm muscles in torqueing task with respect to grip force, stroke rotation and frequency. Ergonom Rural develop 2015:24-32.

60. De Luca CJ. The use of surface electromyography in biomechanics. J Appl Biomech 1992;13(2)135-163.

61. Enoka RM. Neuromechanical basis of kinesiology. Champaign IL: Human Kinetics Book, 1988. 
62. Issurin VB, Tenenbaum G. Acute and residual effects of vibratory stimulation on explosive strength in elite and amateur athletes. J Sports Sci 1999;17(3):177-182.

63. Poston B, Holcomb WR, Guadagnoli MA, Linn LL. The acute effects of mechanical vibration on power output in the bench press. J Strength Cond Res 2007;21(1):199-203.
64. Luo J, Clarke M, McNamara B, Moran K. Influence of resistance load on neuromuscular response to vibration training. J Strength Cond Res 2009;23(2):420-426.

65. Padulo J, Oliva F, Frizziero A, Maffulli N. Muscles, Ligaments and Tendons Journal - Basic principles and recommendations in clinical and field Science Research: 2018 update. MLTJ 2018; 8(3):305-307. 